\title{
Postsecondary campuses responding to record anxiety and depression levels
}

\author{
n Cite as: CMAJ 2017 December 4;189:E1501-2. doi: 10.1503/cmaj.109-5512
}

Posted on cmajnews.com on Nov. 14, 2017.

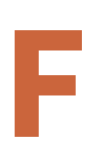
or many university and college students, the initial excitement of the school year quickly gives way to the stress of assignments and midterms. Across Canada, universities and colleges are scrambling to respond to record anxiety and depression levels.

"There's the general way students feel it's overwhelming at times to be at university, but when you start to look at anxiety or depression that's to the point it's difficult to function, that's still a lot of people," said Debbie Bruckner, senior direc- tor of student wellness at the University of Calgary.

In a 2016 survey, $15 \%$ of postsecondary students in Ontario said they'd been treated for depression or diagnosed with it in the previous year. For anxiety, the figure was $18 \%$. This was a large increase from 2013, when $10 \%$ of students reported depression and $12 \%$ reported anxiety.

The growth is due partly to increased stress of postsecondary schooling. "The climate on campuses is different now than 20 years ago," said Bruckner. "There's a

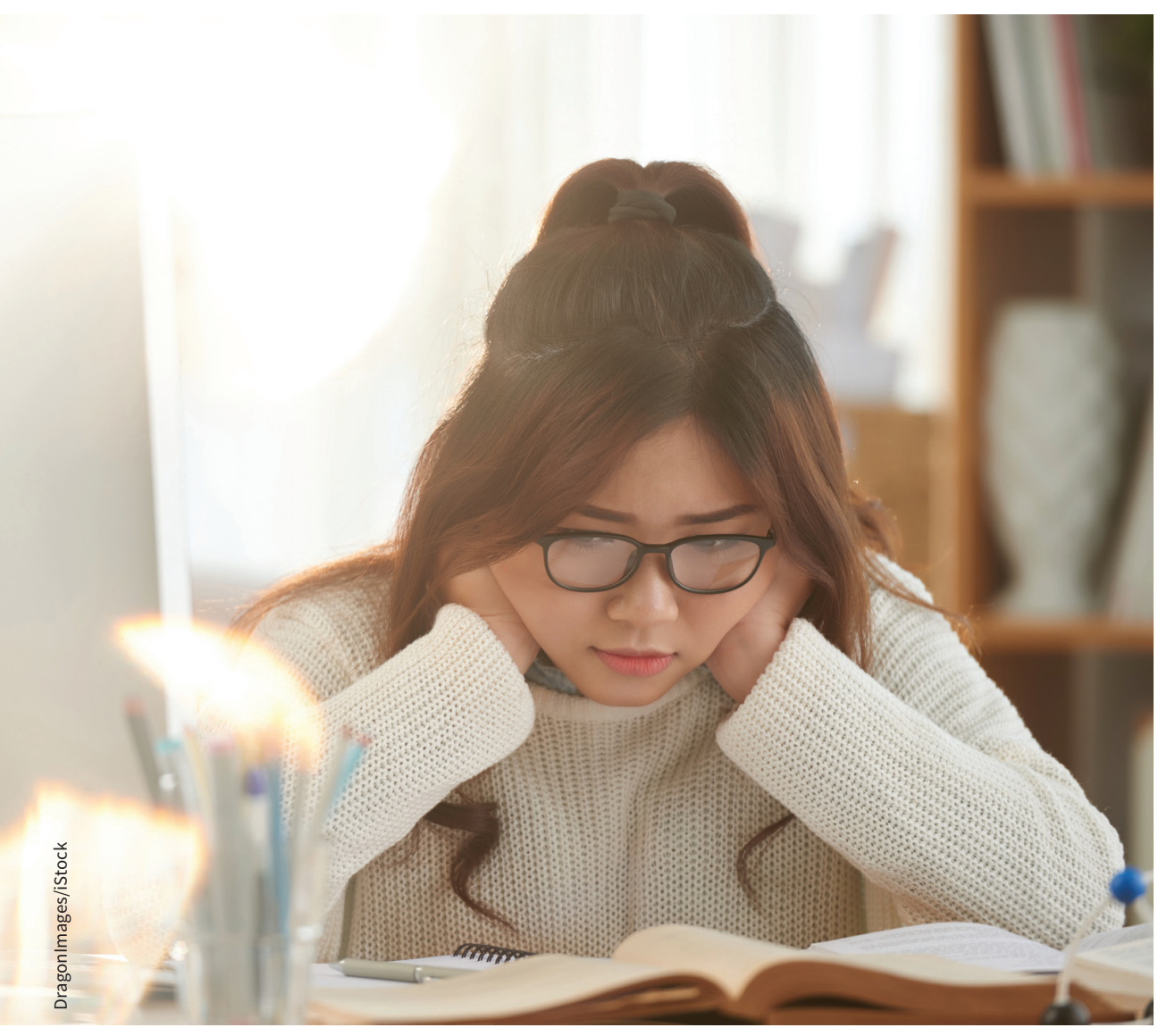

The increasing cost of education, coupled with worry that jobs will remain scarce after graduation, has increased stress levels among postsecondary students. greater financial cost and greater expectations." Reduced stigma about mental health and students' growing awareness about the importance of intervention is also driving demand for mental health services.

Linda Gluck, counselling coordinator at Confederation College, adds that campus mental health services are sometimes seen as the only option. "Here in Thunder Bay, someone can wait up to a year and a half [to see a counsellor], which is three quarters of their academic career."

Provinces are aware of the role campuses are playing in filling the gap. Ontario recently announced an increase in annual funding for campus mental health services from $\$ 9$ million to $\$ 15$ million over the next three years. Alberta promised new campus mental health funding of $\$ 25.8$ million for its 45 universities and colleges.

"We know that mental well-being is linked to academic achievement, learning, retention and future success," said Benjamin Lof, press secretary for the Minister of Advanced Education in Alberta.

Campus mental health services tend to be standalone, with referrals when necessary to provincial services. But Alberta is working to integrate campus mental health services better with regional health systems. According to Lof, this will "help connect students to services they need on and off of campus and will improve transition between locations and services." A 2016 survey found $13.1 \%$ of Alberta postsecondary students seriously considered suicide in the previous year.

With limited funding and large student populations, universities and colleges are finding innovative ways to prevent and respond to mental health crises. More than half of Canadian universities offer 
drop-in sessions with therapy dogs, especially around exam time.

Confederation College in northern Ontario launched video counselling in 2014 to reach students at its eight regional campuses. To ensure confidentiality, students access the video chat on secure computers in designated private rooms.

"At first, the counsellors found video to be awkward, sometimes there is a delay, sometimes the video freezes - but students love the idea," said Gluck. Students are used to video chatting with friends, and feel they can be more open with counsellors who aren't located in their town. The college has also educated employees to recognize and respond to the signs of suicidal thoughts, signs that students might "miss, dismiss or avoid," said Gluck.

The University of Calgary has implemented a 24-hour phone line for students experiencing mental distress. Campus counsellors are available during the day. After hours, students are connected, with their permission, to local counselling and distress services. The university has a formal agreement with community services so their professionals are trained in the common issues students face.

More generally, the university is working to change the culture on campus to reduce student stress, said Bruckner. That means working at every level to promote mental health, whether through adding more green spaces or easing the bureaucratic process for students changing their majors. Mental health services on campuses were once seen as "a fringe benefit," said Bruckner. "Now it's part of everything we do."

Wendy Glauser, Toronto, Ont. 